\title{
Lymphangioma of the Vallecula
}

\author{
James T. Castle
}

Received: 4 October 2010/Accepted: 13 November 2010/Published online: 5 December 2010

(C) Springer Science+Business Media, LLC (outside the USA) 2010

\section{History}

A 47 year-old male presented with a chief complaint of recurrent neck pain, as well as a "shooting pain" which traveled down his arms whenever he coughed or sneezed.

\section{Radiographic Features}

An axial T2-weighted magnetic resonance imaging study of the current case (Fig. 1) revealed a small mucosal based lesion which appeared to be at the level of the left lingual tonsil and involved the vallecula. This mass appeared to be intruding on rather than arising from the vallecula.

\section{Diagnosis}

The hematoxylin and eosin stained surgical specimen (Fig. 2) is composed of variably dense fibrovascular stroma notable for numerous ovoid and irregularly shaped vessels contained within. The vessels are lined by unremarkable, flattened endothelial cells which are widely separated. The supporting collagenous stroma along with the thin lining, occasionally form into thin papillations which project slightly into the luminal space. High power view (Fig. 3) shows thin septations separating the luminal space into compartments which contains thin, frothy, eosinophilic proteinaceous material as well as numerous lymphocytes.

\section{J. T. Castle (更)}

Department Of Oral \& Maxillofacial Pathology, Naval

Postgraduate Dental School, NMMPT\&E, 8901 Wisconsin Ave.,

Bethesda, MD 20889-5611, USA

e-mail: James.Castle@med.navy.mil
These vascular spaces remain superficially placed and do not dissect deep into the connective tissue.

\section{Discussion}

Lymphangiomas are rare congenital lesions of the lymphatic system that occur mainly within the head and neck, particularly in the posterior triangle, but are commonly found within the oral cavity as well [1]. Based on the size of the cavities that are involved in the lesion, classification is separated into variants termed capillary, cavernous, and cystic hygroma. Multiple patterns are frequently noted to be within the same lesion. Capillary and cavernous variants of lymphangioma are confined within dense structural tissue areas whereas, cystic hygroma occur where expansion into large, loculated, cystic spaces can develop, such as within the neck [2].

Involvement of lymphangioma within the larynx is usually the result of direct extension of a congenital lesion originating within the neck, although cases of isolated laryngeal lymphangiomas have been reported as rare entities arising in children and adults [3-8]. The most common location is in the supraglottis within the epiglottis, aryepiglottic folds and arytenoids [8]. Being difficult to diagnose unless the lesion is allowed to grow to a large size, symptoms are non-specific until dyspnea, dysphagia, or a voice change signals a need for further clinical investigation.

The histologic differential diagnosis would include hemangioma and possibly metastatic papillary cystic thyroid carcinoma. Great histologic similarity exists between lymphangioma and hemangioma as both can be capillary sized and show a thin endothelial lining, but in hemangioma, the endothelial cells may appear plumper. Lymphangiomas occasionally show short papillations projecting a 


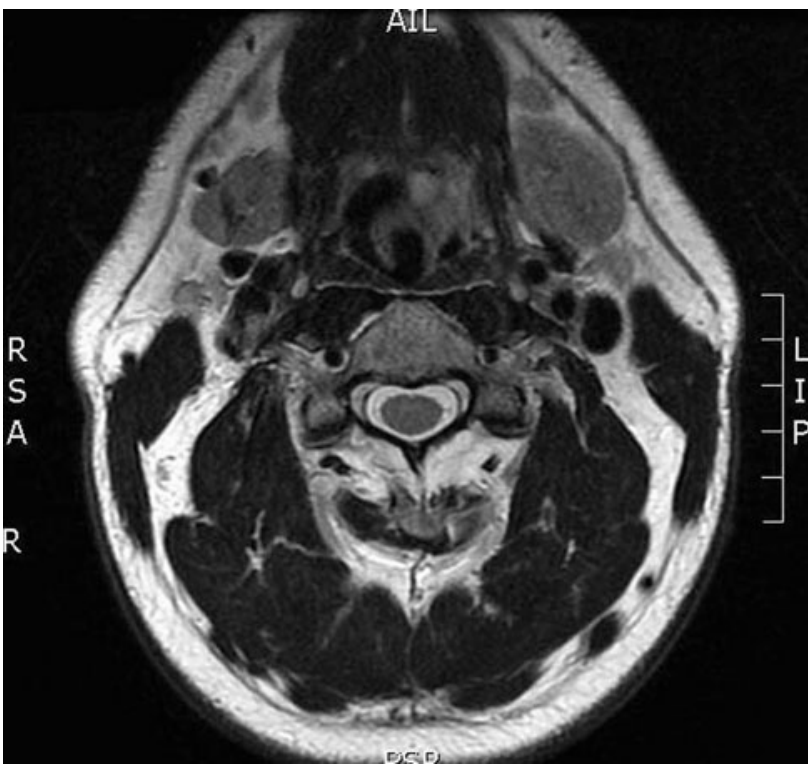

Fig. 1 Axial T2 weighted magnetic resonance image demonstrates a well-circumscribed mass in the area of the left vallecula

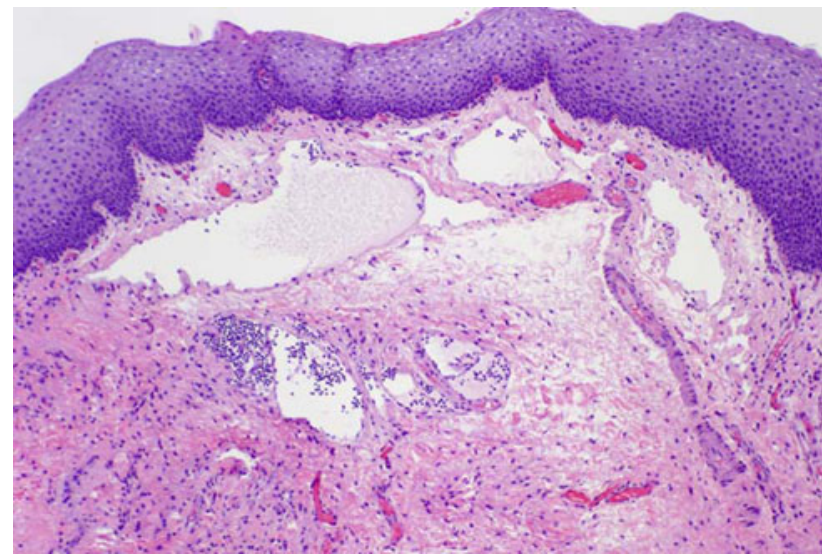

Fig. 2 Histologic appearance of the lymphangioma showing ovoid dilated channels, some of which contain loose eosinophilic material, are contained within a collagenous background stroma

short distance into a luminal area which contains eosinophilic, acellular lymph fluid whereas, hemangioma does not show these sort of papillations and red blood cells can be seen in the luminal area instead. Unfortunately, further distinction is made difficult as the lining of hemangiomas as well as lymphangiomas will react with Factor VIII, CD 31 and CD 34. The lymphatic marker D2-40 can be a distinguishing marker between these two as podoplanin is expressed in lymphatic endothelial cells and not seen in the endothelial lining of hemangiomas [9].

The cystic variant of metastatic papillary thyroid carcinoma as a result of occult papillary thyroid carcinomas or microcarcinomas, may appear in lateral neck locations [10]. Histologically, these tumors may show prominent

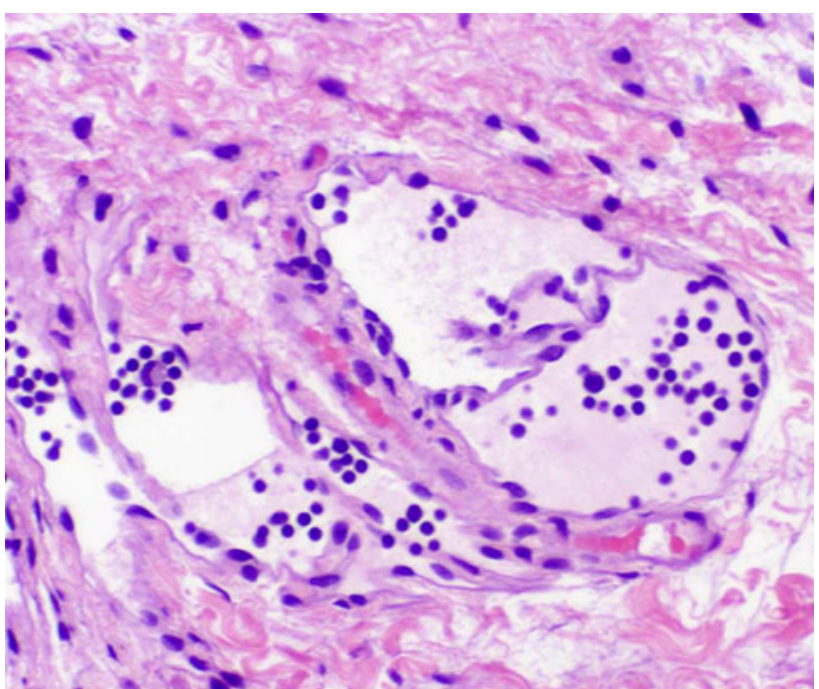

Fig. 3 High power view showing thin-walled lymphatic channels of a single cell thickness, with thin septations dividing the lumen. Abundant eosinophilic, proteinaceous material and numerous lymphocytes are helpful with the diagnosis

cyst formations that are lined by flattened epithelium with a peripheral fibrous wall. Short papillae can be noted to contain the familiar appearing large, ovoid and grooved nuclei with a somewhat ground glass appearance typical of classic appearing papillary thyroid carcinoma. The use of thyroid transcription factor (TTF-1) is helpful if a diagnostic dilemma exists between papillary thyroid carcinoma and lymphangioma.

The radiographic differential diagnosis would include vallecular (retention) cyst, ectopic thyroid, dermoid cyst, thyroglossal duct cyst or hemangioma. Direct flexible laryngoscopy is the primary tool for investigation although examination utilizing ultrasound, computed tomography (CT) or magnetic resonance imaging (MRI) are other available diagnostic tools. Lymphangioma, hemangioma, dermoid cyst and thyroglossal duct cyst all have a similar low-density appearance on CT whereas, being of high density, ectopic thyroid tissue is the only entity distinguishable on CT [11]. Lymphangioma evaluated by ultrasound scanning reports a thin-walled hypoechogenic mass whose size varies based on the volume of collected fluid as compared to hemangioma which shows a translucent mass in which pulsating Doppler flow signals are detected [12]. On MRI, lymphangioma may show a variable sequence on T1-weighted sequences, and high signal on T2-weighted sequences. MRI also allows for better tissue characterization and lesion extent [13].

Surgical resection remains the mainstay of treatment in most cases but total removal is not always possible due to the size of the lesion and involvement of vital structures. Direct injection of lymphangiomas with sclerosant agents has been included as an alternative to reduce the impact 
and complications of surgery. Varying products have been used as sclerosing agents and include sodium morrhuate, dextrose, tetracycline, doxycycline, bleomycin, ethanol, ethibloc, and OK-432 [14]. Some substances can result in unacceptable complications and make future surgical procedures more difficult. The premise behind sclerotherapy is that these agents make subsequent surgical excision easier by reducing the size of the lesion, although use of these agents is usually not what the product was initially intended for [14]. Magnetic resonance guided neodymium: yttrium aluminum garnet laser induced interstitial thermotherapy has been proven as a safe mode of treatment for deep tumors through controlled coagulation necrosis [15].

Although rare, lymphangioma should be considered within the differential diagnosis of laryngeal and epiglottic enlargements not specifically attributed to other causes.

Disclaimer The opinions and assertions expressed herein are those of the authors and are not to be construed as official or representing the views of the Department of the Navy or the Department of Defense. I certify that all individuals who qualify as authors have been listed; each has participated in the conception and design of this work, the writing of the document, and the approval of the submission of this version; that the document represents valid work; that if we used information derived from another source, we obtained all necessary approvals to use it and made appropriate acknowledgements in the document; and that each takes public responsibility for it.

\section{References}

1. Emery PJ, Bailey CM, Evans JN. Cystic hygroma of the head and neck. A review of 37 cases. Laryngol Otol. 1984;98:613-9.
2. Grasso DL, Pelizzo G, Zocconi E, et al. Lymphangiomas of the head and neck in children. Acta Otorhinolaryngol Ital. 2008;28: 17-20.

3. Papsin BC, Evans JN. Isolated laryngeal lymphangioma: a rare cause of airway obstruction in infants. J Laryngol Otol. 1996;110: 969-72.

4. Meyer CM, Bratcher GP. Laryngeal cystic hygroma. Head Neck Surg. 1983;6:706-9.

5. Hollinger PH, Brown WT. Congenital webs, cysts, laryngoceles and other anomalies of the larynx. Ann Otol Rhinol Laryngol. 1973;82:637-42.

6. Cohen SR, Thompson JW. Lymphangiomas of the larynx in infants and children: a survey of pediatric lymphangioma. Ann Otol Rhinol Laryngol. 1986;95(suppl):1-20.

7. Selz PA, Arjmand EM. Laryngeal lymphangioma: a case report of an uncommon entity. Otolaryngol Head Neck Surg. 1998; 118(3):382-4.

8. Seven H, Topuz E, Turgut S. Isolated laryngeal lymphangioma showing the symptoms of acute epiglottitis. Eur Arch Otorhinolaryngol. 2004;261:548-50.

9. Kalof AN, Cooper K. D2-40 immunohistochemistry-so far!. Adv Anat Pathol. 2009;16:62-4.

10. Verge J, Guixá J, Alejo M, et al. Cervical cystic lymph node metastasis as first manifestation of occult papillary thyroid carcinoma: report of seven cases. Head Neck. 1999;21:370-4.

11. Lev S, Lev MH. Imaging of cystic lesions. Radiol Clin North Am. 2000;38:1013-27.

12. Giacalone PL, Boulot P, Descshamps F, et al. Prenatal diagnosis of a multifocal lymphangioma. Prenat Diagn. 1993;13:1133-7.

13. Baert AL. Encyclopedia of diagnostic imaging. New York: Springer; 2008. p. 420.

14. Wiegand S, Eivazi B, Zimmermann AP, et al. Sclerotherapy of lymphangiomas of the head and neck. Head Neck. 2010;24.

15. Vaishali B, Nambiar A, Indudharan R. Lymphangioma of the larynx. J Laryngol Otol. 2007;121:e2. 